\title{
Sociologia e ciências sociais em tempos de austeridade*
}

Frédéric Lebaron**

Resumo: Este artigo tem por objetivo demonstrar a importância da sociologia para a análise das políticas de austeridade em tempos de crises políticas e sociais. Tomando como base a Europa nos anos 2000, mostra-se que as políticas de austeridade fiscal são um objeto científico complexo que deve ser analisado do ponto de vista sociológico e não somente econômico. Lebaron analisa a austeridade como uma crença econômica e como um discurso performativo, mostrando que as representações econômicas - das mais teóricas às mais práticas - desempenham um papel crucial na construção e reprodução da ordem social. São essas representações econômicas que estruturaram as instituições e crenças coletivas nos países europeus principalmente a partir dos anos de 1970 e 1980, período de expansão do neoliberalismo e da financerização. O autor apresenta em seguida os mecanismos e atores da austeridade: os Estados europeus (eurocracias); as instituições e os agentes individuais nesse campo. Em um terceiro ponto, Lebaron critica a noção de "austeridade expansionista" e mostra como o capitalismo financeiro tem tomado cada vez mais o controle de nossas sociedades. Por fim, Lebaron analisa os efeitos sociais da austeridade fiscal com base na ideia de "dinâmica complexa do bem-estar". O autor defende a importância de que sejam criados modelos alternativos que considerem a multidimensionalidade do bem-estar em nossas sociedades.

Palavras-chave: Sociologia econômica. Políticas de austeridade fiscal. Sociedades capitalistas. Eurocracias. Multidimensionalidade do bem-estar.

\section{Sociology and social sciences in times of austerity}

Abstract: This paper aims to demonstrate the importance of sociology for the analysis of austerity policies in times of political and social crises. Referencing the situation in Europe in the 2000s, it is shown that fiscal austerity policies are a complex scientific object that must be analyzed from a sociological rather than a purely economic point of view. Lebaron analyzes austerity as economic belief and performative discourse, showing that economic representations - from the most theoretical to the most practical - play a crucial role in the construction and reproduction of social order. These economic representations have structured institutions and collective beliefs in European countries, especially since the 1970s and 1980s, a period of expansion for neoliberalism and financialization. He then presents the mechanisms of, and participants involved in austerity: the European states (eurocracies), the institutions and the individual agents in this field. In a third instance, Lebaron criticizes the notion of "expansionary austerity" and shows how financial capitalism has increasingly taken control of our societies. Finally, Lebaron analyzes the social effects of fiscal austerity, based on the idea of the "complex dynamics of well-being". The author argues for the importance of creating alternative models that take into consideration the multidimensionality of well-being in our societies.

Keywords: Economic sociology. Fiscal austerity policies. Capitalist societies. Eurocracies. Multidimensionality of well-being.

\author{
* Tradução: Leo \\ Lopes. \\ ** Frédéric Lebaron \\ é professor da École \\ Normale Supérieure \\ de Paris-Saclay (ENS \\ Cachan), Cachan, \\ Val-de-Marne, \\ França, onde dirige \\ o Departamento \\ de Ciências Sociais. \\ <frederic.lebaron@ \\ uvsq.fr>
}




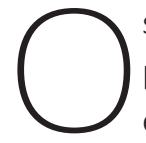
s aspectos das políticas de austeridade são geralmente vistos no espaço público como uma questão estritamente "econômica", e o conhecimento específico dos sociólogos é geralmente desqualificado ou mal reconhecido no que diz respeito a aspectos fiscais, política macroeconômica, avaliação de políticas públicas etc. Até mesmo alguns sociólogos partilham da ideia de que não são competentes neste domínio e é por isso que ainda ouvimos muitas vezes em nosso meio a famosa frase: "Eu não sou um economista, mas...".

Na melhor das hipóteses, pede-se aos sociólogos que avaliem, quantitativa ou qualitativamente, as consequências sociais das decisões fiscais vistas como residuais, o que é obviamente muito importante, como tentarei demonstrar, mas certamente não é suficiente para definir o escopo e a ambição de nossa disciplina (ver, por exemplo, o apelo aos sociólogos como explicadores de "residuais" em modelos macroeconométricos, em Carré, Dubois \& Malinvaud, 1972).

A austeridade não é apenas do interesse político pontual, como muitas vezes se pensa em relação às notícias cotidianas. É claro que reagimos fortemente quando enfrentamos aumentos de impostos e tarifas públicas para a maioria, cortes orçamentários em programas acadêmicos ou de pesquisa, diminuição da oferta de cargos públicos e o consequente aumento da pobreza e precariedade em nossas próprias instituições acadêmicas ou mais amplamente, como ocorre hoje em muitos países. É particularmente o caso na Europa nos anos de 2010 e no Brasil mais recentemente. Há, obviamente, necessidade de uma forte defesa de nossa disciplina, da pesquisa pública e das instituições de ensino superior nestes tempos.

A sociologia como disciplina científica é claramente competente para tomar as "políticas de austeridade" como objetos científicos complexos, ou melhor, tentar construí-las como objetos científicos, como diziam Bourdieu, Chamboredon e Passeron (1968) em seu famoso livro Le métier de sociologue.

Mas a austeridade está ainda mais fundamentalmente relacionada a certa concepção do papel dos Estados nas sociedades capitalistas contemporâneas, uma concepção que foi particularmente revivificada durante o período do neoliberalismo e da "financeirização" na Europa, desde os anos 1970-1980 (Blyth, 2013; Schui, 2014). Austeridade fiscal, associada à luta absoluta contra a inflação, está relacionada com o que os alemães chamam de Weltanschauung (visão do mundo), para a qual as despesas públicas são vistas como excessivos déficits públicos, dívidas públicas como ameaças e limites para desenvolvimentos futuros e seu crescimento como um mecanismo intergeracional que transfere a chamada carga da dívida para as gerações futuras. 
Austeridade é também uma palavra que abarca um universo semântico maior, com implicações simbólico-discursivas. Atores políticos que promovem cortes orçamentários ou aumento generalizado de impostos que afetam os mais pobres geralmente negam a ideia de que praticam "austeridade" e preferem uma narrativa essencialmente metafórica de "restabelecer o equilíbrio", "ajustar a economia para melhorar sua competitividade", enfrentar a dívida pública para a próxima geração ou simplesmente seguir uma regra constitucional. Todos esses interesses devem fazer parte da análise se acreditarmos na dimensão simbólica, portanto discursiva, da vida econômica.

\section{Austeridade como crença econômica e como discurso performativo}

Seguindo Émile Durkheim e alinhado com trabalhos focados em poder simbólico ou performatividade (Pierre Bourdieu, e também nos trabalhos influentes em sociologia econômica como os de Michel Callon e Donald McKenzie), tentei demonstrar que representações econômicas de vários tipos, das mais teóricas (modelos de equilíbrio geral, como ensinados na academia ou utilizados nos bancos centrais) até as mais triviais e práticas (como protestos anti-impostos dos contribuintes) desempenham um papel crucial na construção e reprodução da ordem social (Lebaron, 2000, 2003).

Como crenças coletivas incorporadas nos discursos, as representações econômicas estruturam uma base profunda de nossas instituições, nossos marcos legais, nossas conversas diárias (por exemplo, representações dos níveis relativos e absolutos de preços, eficiência de administração e empresas etc.). Em sociedades onde a religião desempenha um papel menos central e determinante na definição de valores, embora obviamente ainda esteja presente e ainda seja muito influente, minha hipótese é que as crenças econômicas historicamente assumiram este papel e agora tendem a ser dominantes em relação à nossa visão coletiva de valores morais, justiça etc.

Nesse contexto, a ideia de uma necessária neutralidade orçamentária do Estado é um elemento de uma representação coletiva mais ampla, na qual empresas e mercados privados são vistos como fontes de dinamismo e eficiência através da competição, enquanto o Estado é visto apenas como elemento externo regulador e estabilizador (direitos de propriedade), na maioria das vezes como um freio e uma limitação para atores privados. Essa visão econômica tem sido parte de uma desestabilização estrutural dos Estados fiscais e de sua submissão aos mercados financeiros desde a ascensão do neoliberalismo. 
A austeridade foi descrita, por exemplo, por Mark Blyth (2013) como uma ideia antiga que se desenvolveu e se transformou ao longo da história. Na Europa, nunca desapareceu completamente da chamada doutrina tradicional dos tesouros nacionais ou dos bancos centrais, e foi revivificada pela teoria neomonetarista ("expectativas racionais" e "nova macroeconomia clássica") nos anos 1970. No novo cenário que surgiu na década de 1970, os Estados eram vistos como "vampiros" que tendiam a drenar as forças energéticas do mercado, de acordo com uma metáfora desenvolvida por Fred Block (1997).

A história mais geral da difusão de um novo conjunto de crenças - denominado como neoliberal - foi amplamente documentada, embora alguns mecanismos dessa "história de sucesso" (ou "história de fracasso", se preferir) permaneçam bastante complexos. O conjunto inicial de ideias neoliberais foi desenvolvido por um pequeno grupo de intelectuais e acadêmicos, em torno da Société du Mont Pèlerin (Denord, 2007). Mas os bancos centrais, os ministérios das finanças, as instituições de Bretton Woods - Fundo Monetário Internacional (FMI) e Banco Mundial - e a Organização para a Cooperação e Desenvolvimento Econômico (OCDE) foram os principais territórios institucionais de seu grande sucesso a partir da década de 1970, antes de alcançar os governos propriamente ditos. Uma instituição acadêmica, como o Prêmio Nobel em economia, também desempenhou importante papel simbólico e ideológico, como recentemente demonstraram Offer e Söderberg (2016).

Um grande sucesso da doutrina da austeridade tem sido o cenário jurídico da Eurozona, conforme definido no tratado de Maastricht, em 1992, após uma negociação política entre França e Alemanha, com um limite legal para déficits orçamentários fixado em $3 \%$ do PIB, e para dívida pública em 60\% do PIB. Desnecessário dizer que não há fundamento "objetivo" para esses limites, mas eles desempenharam até hoje um efeito performativo muito forte como marco jurídico-constitucional e como referência político-econômica geral. Se você não tiver esses dois números em mente, não poderá entender parte da situação na Zona do Euro e na Europa de hoje.

\section{Os atores da austeridade:} um campo dinâmico

Em investigações recentes com em companhia de um cientista político (Georgakakis \& Lebaron, 2015), tentamos demonstrar que a política de austeridade na Europa, como qualquer esquema de política pública, está inserida em um campo social, que evolui e muda em contextos históricos particulares (Bourdieu, 1992; Fligstein \& McAdam, 2012). Este campo dinâmico é composto por instituições (a Comunidade 
Europeia, o Banco Central Europeu, os ministérios das finanças, os diferentes governos, várias empresas etc.) e atores individuais, com suas trajetórias pessoais e, portanto, com suas disposições e orientações econômicas, que também são determinadas por sua situação e biografia.

Com a crise de 2008, a principal reação dos estados europeus, seguindo os conseIhos do FMI e as políticas lideradas pelos Estados Unidos e pela China, foi permitir que os chamados "estabilizadores automáticos" desempenhassem seu papel e aceitassem um aumento temporário da dívida pública a fim de evitar um colapso do sistema financeiro. Isso deu origem ao que nós, em francês, chamamos de plans de relance (estímulo fiscal), incluindo grandes investimentos em novos edifícios para nossas instituições de pesquisa - na França: plans investissements d'avenir (planos de investimentos para o futuro). Tais estímulos foram menos importantes dentro da Zona do Euro do que em outras regiões do mundo, porque contradizem seu compromisso constitucional com o equilíbrio orçamentário conforme formalizado nos tratados. Os atores políticos conseguiram impor estímulos contra as instituições, argumentando que a situação era excepcional e temporária.

No início de 2010, uma rápida mudança ocorreu no clima político na Zona do Euro. Essa nova alternativa foi lançada publicamente pelo governo alemão e pela Comissão Europeia, em relação a uma nova crise financeira, chamada de "crise da dívida", que afetou a Grécia e os países do sul da Europa. O nível de dívida pública da Grécia estava subindo rapidamente e o medo de um calote estava se espalhando nos mercados financeiros. Nós enfrentamos um rápido aumento do spread incidente nas taxas de juros.

Os mecanismos sociais por trás do processo de restauração da estrutura oficial estão relativamente claros agora. Anteriormente, durante o curto "parêntese keynesiano" do estímulo fiscal, durante o verão de 2009, os atores do Banco Central Europeu começaram a exigir uma volta rápida e brutal à norma. Eles foram, ao mesmo tempo, obrigados a lidar com um novo papel ampliado dos bancos centrais e uma postura mais rígida sobre o equilíbrio orçamentário foi vista como uma contrapartida de uma política monetária muito expansionista. Tornou-se uma espécie de cruzada moral, como muito bem expressou Jürgen Stark (ex-membro do Conselho Executivo do Banco Central Europeu).

Essa cruzada moral foi então apoiada por um pequeno número de atores poderosos, como Wolfgang Schäuble, ministro das Finanças da Alemanha, seguida por Angela Merkel e Nicolas Sarkozy. Então observamos um compromisso muito geral, principalmente na mídia dominante, por um ajuste rápido e massivo. Este ajuste foi 
em primeiro lugar imposto pela chamada "Troika" (Comunidade Europeia, Banco Central Europeu e FMI) aos países "sob o programa da Comissão" - Grécia, Chipre, Irlanda e Portugal.

Em outros países, como a França, o ajuste foi menos brutal e levou a variações mais lentas, e até agora a França tem tido déficit público acima do patamar de 3\%, sem falar em sua dívida pública que se manteve estável após anos de austeridade.

\section{Austeridade, finanças e desigualdade: em direção ao capitalismo financeiro puro?}

A virada brutal em direção à política de austeridade na Europa - entre 2010 e 2013 - foi descrita de vários pontos de vista, como a criação e difusão de um discurso mágico sobre os efeitos benéficos do ajuste orçamentário, descrito como "austeridade expansionista". Paul Krugman tem sido um dos mais precisos críticos dessa nova crença coletiva, legitimada por uma referência à nova macroeconomia clássica e ao uso de Modelos Dinâmicos Estocásticos de Equilíbrio, que falharam em prever uma desaceleração econômica muito mais forte que a esperada (Krugman, 2012).

Essa mudança foi claramente apoiada por atores dos mercados financeiros, já que supostamente estabilizou a situação financeira, especialmente nos países mais afetados pelo aumento das dívidas públicas. É importante notar que isso não pode ser entendido sem uma referência à persistência de políticas monetárias não convencionais, que permitiram que os bancos e as instituições financeiras permanecessem relativamente estáveis e saudáveis após a catástrofe de 2008.

Paralelamente, enfrentamos desde 2010 uma situação de crescimento muito baixo na Zona do Euro, sem sinais de forte recuperação econômica, especialmente em comparação com as demais economias internacionais. As limitadas recentes melhorias nos mercados de trabalho são acompanhadas por um importante aumento nos níveis de pobreza, incluindo mesmo a Alemanha, que supostamente é um modelo vitorioso. Desde 2010, os níveis de lucros e ganhos financeiros mantiveram-se elevados em comparação com a estagnação das remunerações do trabalho.

Este contraste entre um aumento nos lucros e a renda do capital de um lado e os salários estagnados de outro, nos lembra fortemente a lei de Piketty como declarada no Capital in the twenty-first century: tal relação geral é, pelo menos, uma característica dos anos 2010 na Zona do Euro (Piketty, 2013). Mas isso ocorre mais amplamente. É como se as principais características do capitalismo financeiro, que 
já tendiam a dominar, tivessem tomado completamente nossas sociedades desde a grande recessão.

\section{Um caso para o estudo de componentes multidimensionais do bem-estar}

Os efeitos sociais da austeridade são, naturalmente, um caso central para a sociologia, e não há necessidade de escrever muito sobre este ponto, conhecendo a situação atual no Brasil, onde se observa um rápido aumento nos índices de pobreza, uma degradação da posição das classes trabalhadoras e dos grupos marginalizados, numa sociedade profundamente dividida e polarizada.

Depois de Durkheim, Simiand ou Lazarsfeld, deve ficar claro para todos os sociólogos que análises profundas das conexões aproximadas, mas não mecânicas, entre a dinâmica econômica, as políticas públicas e as condições sociais são necessárias, até mesmo por algumas questões esperadas por nossas sociedades, que nos pagam para criar conhecimento e desenvolver também aplicações e soluções. Ambos são um desafio científico e político para a nossa disciplina, especialmente em resposta a avaliações econômicas usuais, na maioria das vezes em favor de uma expansão de mecanismos de mercado ou propostas de redução de custos.

Temos visto um certo renascimento de tais estudos, com epidemiologistas e sociólogos como David Stuckler e Sanjay Basu escrevendo sobre o "corpo econômico" (Stuckler \& Basu, 2013), que é uma maneira de lembrar que as sociedades, compostas de seres humanos, também podem ser vistas como corpos vivos muito complexos, que podem se tornar coletivamente doentes e até morrer em certas circunstâncias. Isso está próximo da ideia de "patologias sociais" de Durkheim, que marcou o nascimento de um novo papel para o sociólogo.

Pode-se acrescentar à sua perspectiva a ideia da multidimensionalidade e uma atenção à dinâmica complexa, inspirada no relatório de Stiglitz, Sen e Fitoussi (2009). Ao utilizar estatísticas oficiais da União Europeia (avaliação European Union Statistics on Income and Living Conditions), Pierre Blavier e eu demonstramos uma dinâmica bastante impressionante de regressão social em relação aos indicadores básicos de padrão de vida e pobreza material na Europa, especialmente em certos países - Grécia, Portugal, Espanha, Itália - e certos grupos sociais menos qualificados, pequenos independentes em alguns casos (Lebaron \& Blavier, 2017).

Tais dinâmicas estão relacionadas com a evolução das taxas de confiança em várias instituições que registaram um declínio acentuado, especialmente entre 2011 e 2014. 
As taxas de abstenção e votos a "populistas de direita" também vêm aumentando desde 2010. Por exemplo, 11 milhões de pessoas votaram em Marine Le Pen na eleição presidencial francesa de maio de 2017, com um recorde de abstenção para esse tipo de eleição.

A pior e mais profunda parte da evolução relacionada à austeridade é, contudo, difícil de apontar apenas através de indicadores oficiais, e relaciona a complexidade/ multidimensionalidade de representações, expectativas pessoais e coletivas, sofrimento subjetivo e material, "misère de position et misère de condition" (Bourdieu, 1993): precisamos de investigações paralelas qualitativas e quantitativas objetivas, utilizando todos os tipos de métodos (etnografia e etnocontabilidade como desenvolvidos por Alain Cottereau (veja Cottereau \& Marzok, 2012; Blavier, 2017) e uma integração entre esquemas explicativos psicológicos e sociológicos, que levem em conta a natureza complexa dos contextos e dinâmicas históricos.

E para concluir brevemente sobre este ponto, apenas novos conhecimentos e novos modelos de inteligibilidade nos permitirão propor novas respostas às perguntas feitas com insistência por nossas sociedades.

\section{Referências}

BLAVIER, P. Les manifestations socio-économiques du chômage de masse et les réaménagements des budgets de ménage pour y faire face. Le cas de la Grande Récession Espagnole (2008-2015). Thèse (Doctorat; Directeurs de thèse: BOURDIEU Jérôme, LEBARON Frédéric) - École des Hautes Études en Sciences Sociales, Paris, 2017.

BLOCK, F. The vampire State. And other myths and fallacies about the U.S. economy, New York: The New Press, 1997.

BLYTH, M. Austerity. The history of a dangerous idea. New York: Oxforf University Press, 2013.

BOURDIEU, P. La misère du monde. Paris: Les Éditions du Seuil, 1993.

— . Les règles de l'art. Genèse et structure du champ littéraire. Paris: Les Éditions du Seuil, 1992.

BOURDIEU, P.; CHAMBOREDON, J.-C.; PASSERON, J.-C. Le métier de sociologue. Paris; Genève: Mouton; Bordas, 1968. 
CARRÉ, J.-J.; DUBOIS, P.; MALINVAUD, E. La croissance française. Un essai d'analyse économique causale de l'après-guerre. Paris: Les Éditions du Seuil, 1972.

COTTEREAU, A.; MARZOK, M. M. Une famille andalouse. Ethnocomptabilite d'une économie invisible. Paris: Bouchene, 2012.

DENORD, F. Néo-libéralisme, version française. Histoire d'une idéologie politique. Paris: Demopolis, 2007.

FLIGSTEIN, N.; MCADAM, D. A theory of fields. Oxford (UK): Oxford University Press, 2012.

GEORGAKAKIS, D.; LEBARON, F. Le champ de la gouvernance économique européenne et les politiques d'austérité (2010-2015): premières esquisses. Communication au colloque de Strasbourg "The economic crisis and the reconfiguration of european actors", v. 4, Nov. 2015.

KRUGMAN, P. End this depression now! New York: W. W. Norton \& Company, 2013.

LEBARON, F. Le savant, le politique et la mondialisation. Bellecombe-en-Bauges (FR): Croquant, 2003.

- La croyance économique. Les économistes entre science et politique. Paris: Les Éditions du Seuil, 2000.

LEBARON, F.; BLAVIER, P. Classes et nations: quelle articulation à l'échelle européenne? Actes de la Recherche en Sciences Sociales, v. 219, n. 4, p. 80-97, 2017.

OFFER, A.; SÖDERBERG, G. The Nobel factor the prize in economics, social democracy, and the market turn. Princeton (NJ): Princeton University Press, 2016.

PIKETTY, Th. Le capital au vingt-et-unième siècle. Paris: Les Éditions du Seuil, 2013.

SHUI, F. Austerity. The great failure. New Haven; London: Yale University Press, 2014.

STIGLITZ, J.; SEN, A.; FITOUSSI, J.-P. Richesse des nations et bien-être des individus. Paris: Odile Jacob, 2009.

STUCKLER, D.; BASU, S. The body economic: why austerity kills. New York: Basic Book, 2013. 